\title{
Helium and Argon Isotopic Studies of Fossil Material and the Theoretical Evolution of He and Ar in Earth's Atmosphere through Time
}

\author{
Yuko Arakawa, Jun-Ichi Matsuda* \\ Department of Earth and Space Science, Graduate School of Science, Osaka University, Toyonaka, Japan \\ Email: *matsuda@ess.sci.osaka-u.ac.jp
}

Received July 31, 2012; revised August 30, 2012; accepted September 28, 2012

\begin{abstract}
We analyzed the elemental concentrations and the isotopic compositions of helium and argon in Cambrian to Jurrassic aged Gastropod, Ammonite and Trilobite fossils in order to examine variation in these gases through time. Fossil samples yielded $\mathrm{He}$ and Ar isotopic ratios close to the present day atmospheric values, but also indicated some addition of a radiogenic component. We compared the results to theoretical values calculated from a mathematical model of Earth's atmosphere assuming mantle degassing. Results from our mathmatical models showed that the ${ }^{40} \mathrm{Ar}{ }^{36} \mathrm{Ar}$ ratio of Earth's atmosphere increased rapidly after the formation of the Earth, but has been almost identical to the present day value for the last $1 \mathrm{Ga}$. For atmospheric helium, model results were consistent with present day atmospheric values, assuming complete helium degassing from the continental crust into the atmosphere. The model suggests that the atmospheric ${ }^{3} \mathrm{He} /{ }^{4} \mathrm{He}$ ratio has remained relatively constant for the last $0.1 \mathrm{Ga}$. Given the similarity between present day and ancient $\mathrm{He}$ and $\mathrm{Ar}$ isotopic ratios, we conclude that the corresponding ratios measured in ancient fossil material may partially reflect composition of the ancient atmosphere and are not necessarily due to contamination by the present day atmosphere.
\end{abstract}

Keywords: Fossils; Argon; Helium; Isotopes; Atmospheric Evolution

\section{Introduction}

The Earth's atmosphere is believed to be secondary in origin, having been produced by degassing from the Earth's interior. This understanding is evident from the lower atmospheric abundances of noble gases relative to the abundances of active gases with similar mass numbers [1]. Noble gas isotopes are often used to trace the degassing history of the Earth's mantle, and various models have been proposed based on their abundances and isotopic ratios (e.g. [2]). We previously proposed a model for noble gas transfer from Earth's interior [3,4] based on the finding that the lower mantle has experienced an extensive degassing history [5].

Most mantle degassing models calculate the hypothetical isotopic trajectories for noble gases in the mantle (e.g. [6]), but few have addressed the isotopic evolution of atmospheric helium and argon through Earth's history. Noble gas models, including the one described here, assume that the Earth began its existence with the planetary helium isotopic ratio $\left({ }^{3} \mathrm{He} /{ }^{4} \mathrm{He}=\sim 10^{-4}\right)$, which differs from the ${ }^{3} \mathrm{He} /{ }^{4} \mathrm{He}$ ratio of the present mantle $\left(\sim 10^{-5}\right)$ by an order of magnitude, and from that of the present at-

${ }^{*}$ Corresponding author. mosphere $\left(1.4 \times 10^{-6}\right)$ by two orders of magnitude. If ancient terrestrial samples show ${ }^{3} \mathrm{He} /{ }^{4} \mathrm{He}$ and ${ }^{40} \mathrm{Ar} /{ }^{36} \mathrm{Ar}$ ratios similar to modern atmospheric ratios, it is very likely that this finding is attributed to present day atmospheric contamination. This interpretation assumes that ancient $\mathrm{He}$ and $\mathrm{Ar}$ isotopic ratios were markedly different than present day values. In the absence of viable gas inclusions from which pristine $\mathrm{He}$ and $\mathrm{Ar}$ isotopic values could be measured, the precise value of these isotopic ratios in the ancient atmosphere remains unknown.

This report examines the potential use of fossil material as a record for atmospheric He and Ar evolution through time. We begin with the hypothesis that fossil material may contain ancient gas signatures within their internal void spaces. To test this hypothesis, we measured the $\mathrm{He}$ and $\mathrm{Ar}$ isotopic ratios of crushed samples of varying age and compared our results to those estimated from a model of atmospheric He and Ar isotopic evolution through time.

\section{Noble Gas Analysis of Fossils}

\subsection{Samples and Experimental Methods}

Samples used in this study included Gastropod, Ammon- 
ite, and Trilobite fossils of Cambrian to Jurassic age. Samples were obtained through commercial sample collections. Sample names, weights and the localities are given in Table 1. Samples weighed between 5 to $38 \mathrm{~g}$, and had an average size of about $3 \times 5 \mathrm{~cm}$. To capture noble gases potentially encapsulated in the internal void space of these samples, we crushed the samples under vacuum using a closed system crushing device specifically built in our laboratory to process large tektite samples [7]. The sample chamber of the crushing device is a stainless steel cylinder with a diameter of $10 \mathrm{~cm}$ and a height of $10 \mathrm{~cm}$. An airtight piston is inserted into the chamber by turning a handle that slowly crushes the sample. This device makes it possible to reduce a large sample into fine scale fragments (Figure 1), extract noble gases and analyze them within a closed system.

The crusher directly connects to a purification system and a VG5400 noble gas mass spectrometer. The purification system consists of two Ti-Zr getters held at $700^{\circ} \mathrm{C}$, and a cryogenic cold trap which separates $\mathrm{He}$ and $\mathrm{Ar}$ fractions. Further details concerning the purification system and the noble gas measurements can be found in Matsuda et al. [8,9]. Elemental concentrations and isotopic ratios for He and Ar were corrected to procedural blanks analyzed before each sample measurement. The measured concentrations of procedural cold blanks for
${ }^{4} \mathrm{He}$ (and ${ }^{3} \mathrm{He}$ ) were effectively zero, and those for ${ }^{36} \mathrm{Ar}$ were 0.6 to $4.2 \times 10^{-11} \mathrm{~cm}^{3}$ STP. The noble gas concentrations of the samples were normalized to the original sample weights. The uncertainty for the noble gas concentration was about $10 \%$. Helium isotopic ratios were calibrated using the HESJ internal He Standard [10] and Ar isotopic ratios were calibrated using a pipetted air (atmospheric values).

\subsection{Results}

The results for sample $\mathrm{He}$ and Ar concentrations and isotopic ratios are given in Table $\mathbf{1}$.

We plotted the ${ }^{4} \mathrm{He}$ and ${ }^{40} \mathrm{Ar}$ concentrations in Figure 2 along with theoretical and atmospheric envelopes for ${ }^{40} \mathrm{Ar}$ and ${ }^{4} \mathrm{He}$ values. The theoretical ${ }^{40} \mathrm{Ar}-{ }^{4} \mathrm{He}$ space was constructed according to assumptions and calculations described below. The ${ }^{4} \mathrm{He}$ isotope is produced by radiogenic decay of ${ }^{238} \mathrm{U},{ }^{235} \mathrm{U}$ and ${ }^{232} \mathrm{Th}$. The ${ }^{40} \mathrm{Ar}$ isotope forms from ${ }^{40} \mathrm{~K}$ (electron capture). The amounts of radiogenic ${ }^{4} \mathrm{He}$ and ${ }^{40} \mathrm{Ar}\left(\left[{ }^{4} \mathrm{He}\right]_{\mathrm{rad}}\right.$ and $\left.\left[{ }^{40} \mathrm{Ar}\right]_{\mathrm{rad}}\right)$ are written as follows:

$$
\begin{aligned}
{\left[{ }^{4} \mathrm{He}\right]_{\mathrm{rad}}=} & \left(8 \lambda\left[{ }^{238} \mathrm{U}\right]+7 \lambda^{\prime}\left[{ }^{235} \mathrm{U}\right]+6 \lambda^{\prime \prime}\left[{ }^{232} \mathrm{Th}\right]\right) t, \\
& {\left[{ }^{40} \mathrm{Ar}\right]_{\mathrm{rad}}=\lambda_{e}\left[{ }^{40} \mathrm{~K}\right] t }
\end{aligned}
$$

\begin{tabular}{|c|c|c|c|c|c|c|c|}
\hline Sample & {$\left[{ }^{4} \mathrm{He}\right]$} & ${ }^{3} \mathrm{He} /{ }^{4} \mathrm{He}$ & {$\left[{ }^{36} \mathrm{Ar}\right]$} & ${ }^{38} \mathrm{Ar} /{ }^{36} \mathrm{Ar}$ & ${ }^{40} \mathrm{Ar} /{ }^{36} \mathrm{Ar}$ & ${ }^{40} \mathrm{Ar} /{ }^{36} \mathrm{Ar}_{\text {corrected }}{ }^{*}$ & Note \\
\hline & $\times 10^{-11} \mathrm{~cm}^{3} \mathrm{STP} / \mathrm{g}$ & $\times 10^{-6}$ & $\times 10^{-11} \mathrm{~cm}^{3} \mathrm{STP} / \mathrm{g}$ & & & & \\
\hline $\begin{array}{c}\text { Gastropod } \\
\text { (9.68618 g) }\end{array}$ & 35 & $<6.1$ & 110 & $\begin{array}{c}0.1882 \\
\pm 0.0052\end{array}$ & $\begin{array}{c}299.0 \\
\pm 6.0\end{array}$ & $\begin{array}{l}298.4 \\
\pm 17.4\end{array}$ & $\begin{array}{l}\text { Turbo sp. } \\
\text { Albian, Fredericksburg Fm., } \\
\text { Early Cretaceous period }\end{array}$ \\
\hline $\begin{array}{c}\text { Ammonite } \\
\text { (32.73537 g) }\end{array}$ & 870 & $\begin{array}{c}0.170 \\
\pm 0.049\end{array}$ & 1000 & $\begin{array}{c}0.1836 \\
\pm 0.0019\end{array}$ & $\begin{array}{c}280.6 \\
\pm 1.7\end{array}$ & $\begin{array}{c}294.4 \\
\pm 6.2\end{array}$ & $\begin{array}{l}\text { Perisphinctes sp. } \\
\text { Tulear, Madagascar, } \\
\text { Jurassic period }\end{array}$ \\
\hline $\begin{array}{c}\text { Ammonite } \\
\text { (19.39876 g) }\end{array}$ & 540000 & $\begin{array}{c}0.361 \\
\pm 0.106\end{array}$ & 420 & $\begin{array}{c}0.1829 \\
\pm 0.0018\end{array}$ & $\begin{array}{c}315.9 \\
\pm 2.0\end{array}$ & $\begin{array}{c}331.9 \\
\pm 6.0\end{array}$ & $\begin{array}{l}\text { Goniatite sp. } \\
\text { Middle Devonian- } \\
\text { Permian period, }\end{array}$ \\
\hline $\begin{array}{c}\text { Trilobita } \\
\text { (5.49984 g) }\end{array}$ & 4500 & $\begin{array}{c}0.212 \\
\pm 0.058\end{array}$ & 48 & $\begin{array}{c}0.1922 \\
\pm 0.0054\end{array}$ & $\begin{array}{l}380.2 \\
\pm 7.6\end{array}$ & $\begin{array}{l}367.0 \\
\pm 18.6\end{array}$ & $\begin{array}{l}\text { Flexicalymene retrosa } \\
\text { Cincinnatian, Arnheim Fm., } \\
\text { Late Ordovician period }\end{array}$ \\
\hline $\begin{array}{c}\text { Trilobita } \\
\text { (18.09444 g) }\end{array}$ & 220 & $\begin{array}{c}2.7 \\
\pm 1.8\end{array}$ & 7.6 & $\begin{array}{c}0.1901 \\
\pm 0.0052\end{array}$ & $\begin{array}{c}368.9 \\
\pm 7.2\end{array}$ & $\begin{array}{l}362.3 \\
\pm 17.9\end{array}$ & $\begin{array}{l}\text { Homotelus bromidensis ESKER } \\
\text { Mohawkian, Bromide Fm., } \\
\text { Middle Ordovician period }\end{array}$ \\
\hline $\begin{array}{c}\text { Trilobita } \\
\text { (9.10144 g) }\end{array}$ & 9500 & $\begin{array}{c}0.158 \\
\pm 0.029\end{array}$ & 150 & $\begin{array}{c}0.1879 \\
\pm 0.0052\end{array}$ & $\begin{array}{c}320.4 \\
\pm 6.3\end{array}$ & $\begin{array}{l}320.7 \\
\pm 17.5\end{array}$ & $\begin{array}{l}\text { Asaphiscus wheeleri (MEEK) } \\
\text { Wheeler Shale Fm., } \\
\text { Middle Cambrian period }\end{array}$ \\
\hline Air & & 1.399 & & 0.188 & 295.5 & & \\
\hline
\end{tabular}

Table 1. Concentrations and isotopic ratios of $\mathrm{He}$ and Ar in fossils.

${ }^{*}$ We corrected for the mass fractionation effect by calculating a ${ }^{40} \mathrm{Ar} /{ }^{36} \mathrm{Ar}_{\text {corrected }}$ ratio when the ${ }^{38} \mathrm{Ar} /{ }^{36} \mathrm{Ar}$ ratio is 0.188 (see text). 


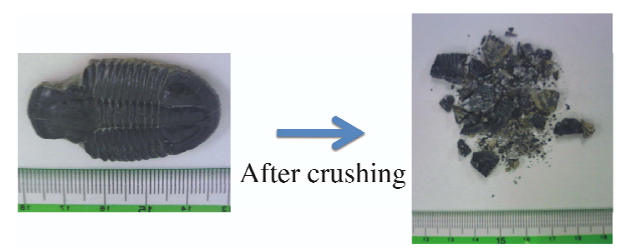

Figure 1. A trilobite sample before and after the crushing. The sample was an Asaphitscus wheeleri specimen from the Middle Cambrian period.

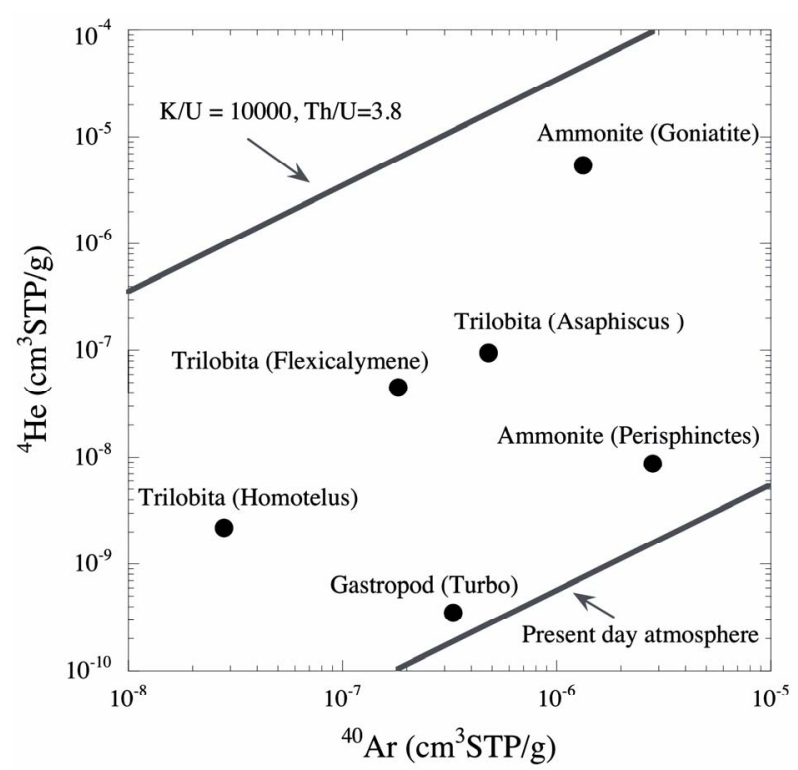

Figure 2. The measured ${ }^{4} \mathrm{He}$ and ${ }^{40} \mathrm{Ar}$ contents of crushed fossil samples shown in ${ }^{4} \mathrm{He}-{ }^{40} \mathrm{Ar}$ space. The line labeled "present day atmosphere" shows present day atmospheric ratios for ${ }^{4} \mathrm{He}$ and ${ }^{40} \mathrm{Ar}$. The upper line gives these ratios calculated from $\mathrm{K} / \mathrm{U}=\mathbf{1 0 , 0 0 0}$ and $\mathrm{Th} / \mathrm{U}=3.8$ (see text).

where bracketed terms refer to absolute amounts of the individual nuclide, $t$ is time, and $\lambda \lambda^{\prime}, \lambda^{\prime \prime}$ and $\lambda_{e}$ are decay constants for ${ }^{238} \mathrm{U},{ }^{235} \mathrm{U},{ }^{232} \mathrm{Th}$, and ${ }^{40} \mathrm{~K}$ (electron capture), respectively. The upper continental crust and Archean bulk crust have a Th/U ratio of about 3.8 [11]. The amount of $\left[{ }^{4} \mathrm{He}\right]_{\mathrm{rad}}$ can thus be represented only by $\left[{ }^{238} \mathrm{U}\right]$ as

$$
\left[{ }^{4} \mathrm{He}\right]_{\mathrm{rad}}=\left(8 \lambda+5.1 \times 10^{-2} \lambda^{\prime}+23 \lambda^{\prime \prime}\right)\left[{ }^{238} \mathrm{U}\right] t .
$$

The K/U ratio for the upper continental crust is 10,000 , and is assumed to be the same for the Archean bulk crust [11]. As the mantle $\mathrm{K} / \mathrm{U}$ ratio is estimated to be 12,700 [12], the elemental fractionation between $\mathrm{K}$ and $\mathrm{U}$ is similar under different conditions. Thus we get the following equation by eliminating time $t$ and using $\mathrm{K} / \mathrm{U}=$ 10,000 from the two Equations (2) and (3),

$$
\left[{ }^{4} \mathrm{He}\right]_{\mathrm{rad}}=35\left[{ }^{40} \mathrm{Ar}\right]_{\mathrm{rad}} \text {. }
$$

The new expression for ${ }^{4} \mathrm{He}$ does not depend on time, and is represented by the upper line plotted in Figure 2.
Assuming closed systems for radiogenic ${ }^{4} \mathrm{He}$ and ${ }^{40} \mathrm{Ar}$ for the crust (and the whole Earth), the encapsulated ${ }^{4} \mathrm{He}$ and ${ }^{40} \mathrm{Ar}$ contents should lie on this line. Present day atmospheric compositions would be located below this line reflecting He loss from the atmosphere to space. The data points of fossils in this study are situated between the upper line and the present day atmospheric line below (Figure 2). We interpret the position of the empirical data (between the upper and lower ${ }^{4} \mathrm{He}-{ }^{40} \mathrm{Ar}$ envelopes) as evidence that the He and Ar contents of the fossil samples reflect ancient atmospheric compositions, assuming some degree of ${ }^{4} \mathrm{He}$ loss from the ancient atmosphere.

All samples gave reasonable $\mathrm{He}$ and Ar isotopic ratios except for the Gastropod sample, which yielded only a trivial amount of ${ }^{3} \mathrm{He}$. The ${ }^{3} \mathrm{He} /{ }^{4} \mathrm{He}$ ratio of this sample could therefore be given only as an upper limit. Measured values for the stable $\mathrm{Ar}$ isotopes $\left({ }^{38} \mathrm{Ar} /{ }^{36} \mathrm{Ar}\right.$ ratio) varied relative to the expected value of 0.188 (Table 1). We interpret variation relative to the ${ }^{38} \mathrm{Ar} /{ }^{36} \mathrm{Ar}$ constant as a mass fractionation effect that occurred during the trapping stage of the gas at the void space in fossil material. We corrected for the mass fractionation effect by calculating a ${ }^{40} \mathrm{Ar} /{ }^{36} \mathrm{Ar}_{\text {corrected ratio based on the }{ }^{38} \mathrm{Ar} /{ }^{36} \mathrm{Ar}}$ ratio in Table 1. The obtained values are close to the present day ${ }^{40} \mathrm{Ar} /{ }^{36} \mathrm{Ar}$ ratio of the atmosphere (295.5) with some variation. Certain higher values are interpreted to reflect the addition of radiogenic ${ }^{40} \mathrm{Ar}$.

Similarly, the measured ${ }^{3} \mathrm{He} /{ }^{4} \mathrm{He}$ ratios are lower than the present day atmospheric value due to the addition of radiogenic ${ }^{4} \mathrm{He}$. The crushing apparatus and procedures used here were intended to exclude radiogenic material issuing from solid parts of the fossil but previous studies using the same technique have demonstrated that some inclusion of a radiogenic component in inevitable (e.g. [13]). The effect of the addition of radiogenic component is larger for He than for Ar. At any rate, considering that He isotopic ratios generally change in orders, the measured ${ }^{3} \mathrm{He} /{ }^{4} \mathrm{He}$ ratios were close to the present day atmospheric value with some addition of a radiogenic component. Ancient terrestrial samples often exhibit $\mathrm{He}$ and $\mathrm{Ar}$ isotopic ratios similar to those of the present day atmosphere, which are generally interpreted to reflect the present day atmospheric contamination. Although this interpretation fits the criterion of simplicity, it assumes that ancient atmospheric He and $\mathrm{Ar}$ isotopic ratios were markedly different than present day values. Below, we will assess this assumption through mathematical modeling of atmospheric He and Ar through time.

\section{Mathematical Modeling of He and Ar Isotopic Ratios in the Atmosphere}

\subsection{Model Assumptions and Construction}

The model used here is based on our previously pub- 
lished work concerning He and Ar dynamics in the mantle $[3,4]$. The model assumes that the Earth was initially uniform in composition but was subsequently divided into three separate reservoirs: the degassed or depleted mantle (Mid-Oceanic Ridge Basalt; MORB source), the less-depleted mantle (Oceanic Island Basalt; OIB source), and the surface reservoir (crust and atmosphere). Individual elements are exchanged through mass flow between reservoirs, and velocities decrease exponentially as a function of time. We treated the decrement factor as a variable parameter, and used the steady-state flow model proposed by Porcelli and Wasserburg $[14,15]$.

Mass flow from the depleted and less-depleted mantle reservoirs to the surface reservoir ( $M_{\text {Dout }}$ and $M_{\text {Lout }}$, respectively) decreases as a function of time $t$ with the decrement factors $\beta_{\mathrm{D}}$ and $\beta_{\mathrm{L}}$, respectively, as follows:

$$
\begin{gathered}
M_{\text {Dout }}(t)=M_{\text {Dout }}(0) \exp \left(-\beta_{\mathrm{D}} \cdot t\right), \\
M_{\text {Lout }}(t)=M_{\text {Lout }}(0) \exp \left(-\beta_{\mathrm{L}} \cdot t\right) .
\end{gathered}
$$

Only solid elements were assumed to be recycled into the mantle with an extraction factor, $r$. Noble gases were not recycled in the mantle because of the subduction barrier for noble gases $[16,17]$. Continental crust was assumed to be produced at a constant rate throughout the Earth's history, and radioactive elements such as U, Th, and $\mathrm{K}$ were transferred from the depleted reservoir to the continental crust with an extraction factor, $x$.

We estimated values for $\beta_{\mathrm{D}}, \beta_{\mathrm{L}}$, and $x$ based on representative ${ }^{3} \mathrm{He} /{ }^{4} \mathrm{He}$ and ${ }^{40} \mathrm{Ar} /{ }^{36} \mathrm{Ar}$ ratios from MORB and OIB source reservoirs: ${ }^{3} \mathrm{He} /{ }^{4} \mathrm{He}=1.1 \times 10^{-5}$ and ${ }^{40} \mathrm{Ar} /{ }^{36} \mathrm{Ar}=6 \times 10^{4}$ in MORB; and ${ }^{3} \mathrm{He} /{ }^{4} \mathrm{He}=4.7 \times 10^{-5}$ and ${ }^{40} \mathrm{Ar}{ }^{36} \mathrm{Ar}=3 \times 10^{3}$ in OIB [5,18-20]. The planetary ${ }^{3} \mathrm{He} /{ }^{4} \mathrm{He}$ ratio $\left(1.41 \times 10^{-4}\right)$ was used as the initial ${ }^{3} \mathrm{He} /{ }^{4} \mathrm{He}$ ratio. The extraction factor $x$ was estimated from the present ${ }^{40} \mathrm{~K}$ concentration in bulk continental crust $\left(3.6 \times 10^{16}\right.$ atoms/g [21]) and in MORB $\left(1.8 \times 10^{14}\right.$ atoms/g [12]). The restricted values for $\beta_{\mathrm{L}}, \beta_{\mathrm{D}}$, and $x$ are 1.32 to $1.34 \times 10^{-9}, 2.60$ to $3.32 \times 10^{-10}$, and 40 to 274, respectively [4]. Further details of the model parameters are given in Kamijo et al. [3] and Seta et al. [4].

\subsection{Atmospheric Argon Isotopic Ratios}

The total amounts of ${ }^{36} \mathrm{Ar}$ and ${ }^{40} \mathrm{Ar}$ in the atmosphere at time $t$ are described by the following equations:

$$
\begin{aligned}
d^{36} \mathrm{Ar}_{\mathrm{A}}(t) / d t= & { }^{36} C_{\mathrm{D}} \cdot M_{\text {Dout }}(t) \\
& +{ }^{36} \mathrm{Ar} C_{\mathrm{L}} \cdot M_{\text {Lout }}(t), \\
d^{40} \mathrm{Ar}_{\mathrm{A}}(t) / d t= & { }^{40} \mathrm{Ar} C_{\mathrm{D}} \cdot M_{\text {Dout }}(t) \\
& +{ }^{40} \mathrm{Ar} C_{\mathrm{L}} \cdot M_{\text {Lout }}(t),
\end{aligned}
$$

where $C$ is the concentration of species represented by the associated superscript, and the subscripts A, D, and L represent the atmosphere, depleted mantle, and less-depleted mantle reservoirs, respectively.

From these equations we can calculate ${ }^{36} \mathrm{Ar}$ and ${ }^{40} \mathrm{Ar}$ concentrations and the ${ }^{40} \mathrm{Ar} /{ }^{36} \mathrm{Ar}$ ratio of the atmosphere through time. The results are shown in Figure 3. The observed ${ }^{40} \mathrm{Ar} /{ }^{36} \mathrm{Ar}$ ratio for the present day atmosphere is identical to the calculated model value due to its use as a boundary condition input to the model. The two lines in Figure 3 are derived from present-day concentrations of ${ }^{40} \mathrm{~K}$ in the continental crust and in the depleted mantle, corresponding to the upper and lower limits for this parameter [4]. As seen in Figure 3(a), ${ }^{36} \mathrm{Ar}$ abundance rapidly increases during the first 1 billion years and is almost constant thereafter. The increase in ${ }^{40} \mathrm{Ar}$ abundance through time is more steady due to the addition of radiogenic ${ }^{40} \mathrm{Ar}$ from ${ }^{40} \mathrm{~K}$. The ${ }^{40} \mathrm{Ar}{ }^{36} \mathrm{Ar}$ ratio in the atmosphere increased very rapidly since the formation of the Earth and has been almost constant for the last 1 billion years (within $4 \%$ of the present day atmospheric value).

\subsection{Atmospheric Helium Isotopic Ratio}

Calculating the atmospheric He isotope ratio through time requires compensation for He escape into space. To incorporate these conditions, we added an escape term in the form of a simple first-order rate equation. The total amounts of ${ }^{3} \mathrm{He}$ and ${ }^{4} \mathrm{He}$ in the atmosphere at time $t$ are described by the following equations:

$$
\begin{aligned}
d^{3} \mathrm{He}_{\mathrm{A}}(t) / d t= & { }^{3} C_{\mathrm{D}} \cdot M_{\text {Dout }}(t) \\
& +{ }^{3} \mathrm{He} C_{\mathrm{L}} \cdot M_{\text {Lout }}(t)-k_{1} \cdot{ }^{3} \mathrm{He}_{\mathrm{A}}(t), \\
d^{4} \mathrm{He}_{\mathrm{A}}(t) / d t= & { }^{4}{ }^{4} C_{\mathrm{D}} \cdot M_{\text {Dout }}(t) \\
& +{ }^{4} \mathrm{He} C_{\mathrm{L}} \cdot M_{\text {Lout }}(t)-k_{2} \cdot{ }^{4} \mathrm{He}_{\mathrm{A}}(t),
\end{aligned}
$$

where $k_{1}$ and $k_{2}$ are the escape coefficients for ${ }^{3} \mathrm{He}$ and ${ }^{4} \mathrm{He}$, respectively. In addition to Jeans thermal escape, non-thermal escape may occur due to the photoionization of He and the interaction of He with the magnetic field [22]. Ozima and Podosek [23] summarized the major fluxes of the total escape for ${ }^{3} \mathrm{He}$ and ${ }^{4} \mathrm{He}$ as 10.1 atoms $\mathrm{cm}^{-1} \cdot \mathrm{s}^{-1}$ and $3.06 \times 10^{-6}$ atoms $\mathrm{cm}^{-1} \cdot \mathrm{s}^{-1}$, respectively. The values for $k_{1}$ and $k_{2}$ were calculated from these fluxes as $1.20 \times 10^{-6}$ year $^{-1}$ and $8.64 \times 10^{-7}$ year $^{-1}$, respectively. Note that these values were independently obtained from the present atmospheric helium budget. As the nonthermal escape flux is considerably larger than that of the thermal escape (especially for ${ }^{4} \mathrm{He}$ ) and does not depend on the temperature of the Earth, we assumed that $k_{1}$ and $k_{2}$ are constant through the time.

Using the above values, we obtain the results shown in Figure 4. Both ${ }^{3} \mathrm{He}$ and ${ }^{4} \mathrm{He}$ abundance rapidly increased during the first several million years and then decreased 

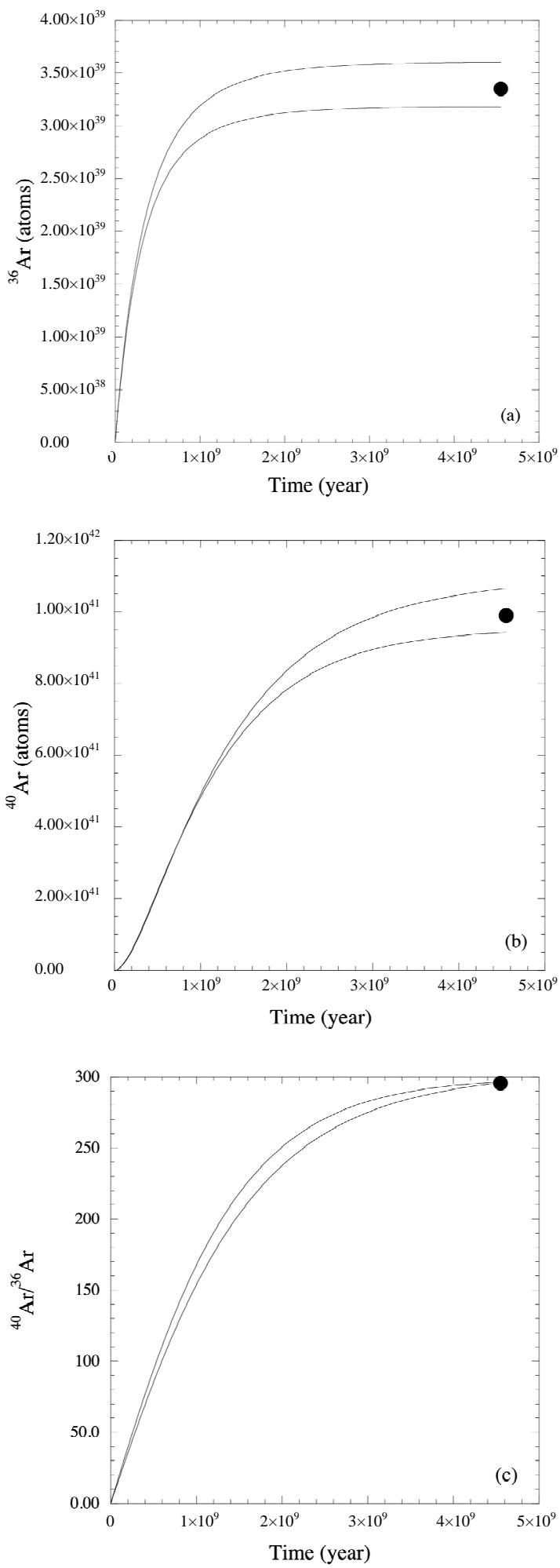

Figure 3. Time versus (a) ${ }^{36} \mathrm{Ar}$ abundance (atoms); (b) ${ }^{40} \mathrm{Ar}$ abundance (atoms); and (c) ${ }^{40} \mathrm{Ar} /{ }^{36} \mathrm{Ar}$ ratio in the atmosphere. The two lines correspond to the upper and lower limits derived from the present day concentration of ${ }^{40} \mathrm{~K}$ in the continental crust and in the depleted mantle (for details, see [4]). The closed circle represents the observed present day atmospheric values.
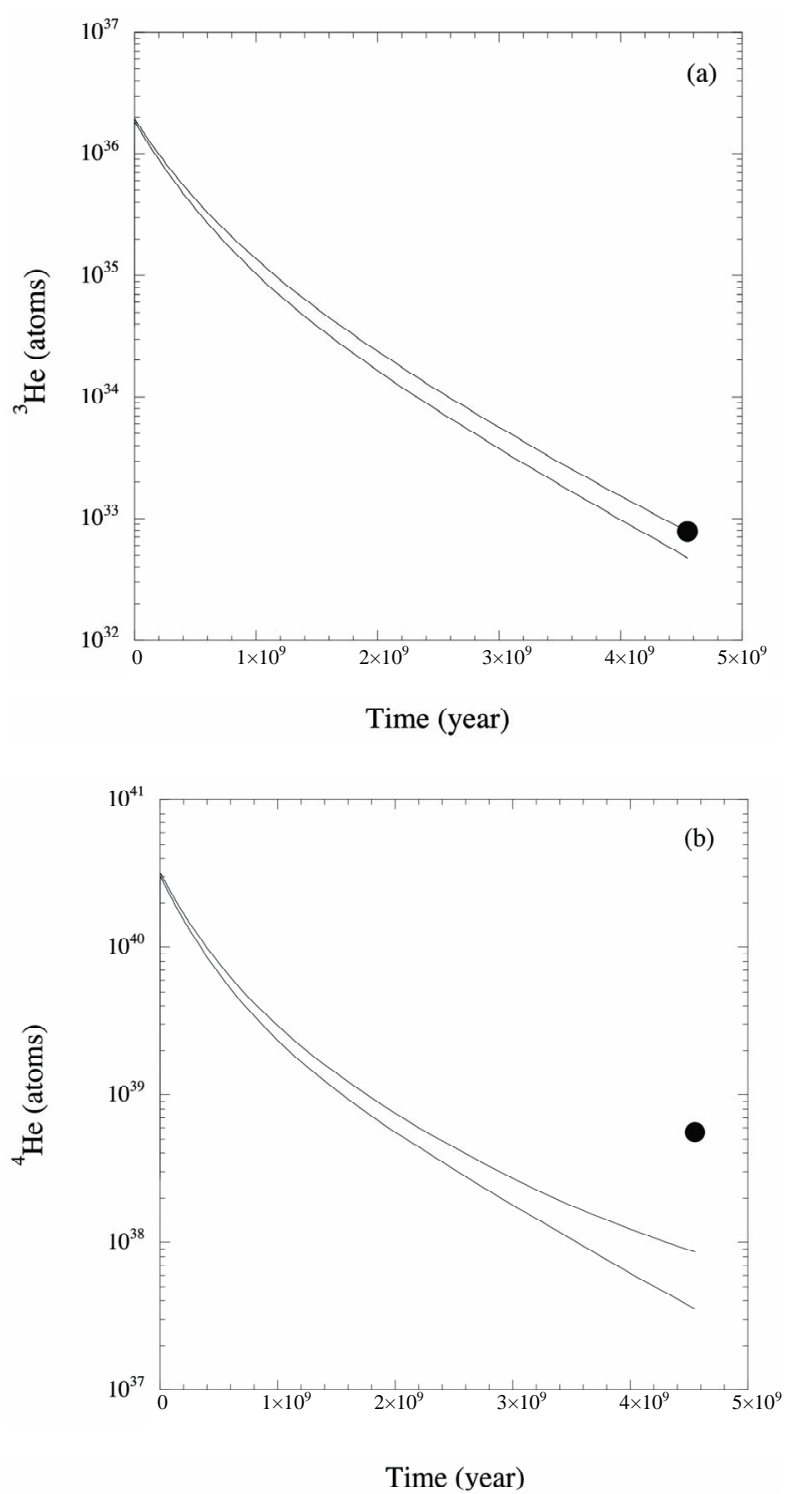

Figure 4. Time versus (a) ${ }^{3} \mathrm{He}$ abundance (atoms) and (b) ${ }^{4} \mathrm{He}$ abundance (atoms) in the atmosphere, with no helium degassing from the continental crust. The two lines correspond to the upper and lower limits derived from the present day concentration of ${ }^{40} K$ in the continental crust and in the depleted mantle (for details, see [4]). The closed circle represents the observed present day atmospheric values.

slowly due to thermal and non-thermal escape. The escape term describes a relatively efficient process for He, and a less efficient process for the more refractory Ar (Figures 3(a) and (b)). The calculated present day atmospheric ${ }^{3} \mathrm{He}$ value is in good agreement with the observed atmospheric ${ }^{3} \mathrm{He}$ abundance (Figure 4(a)). The calculated present day atmospheric ${ }^{4} \mathrm{He}$ value however is about an order of magnitude lower than the corresponding observed ${ }^{4} \mathrm{He}$ value (Figure 4(b)). Our $k_{1} / k_{2}$ ratio is 1.39, which is slightly higher than the simple mass 
square root ratio $\left((4 / 3)^{1 / 2}=1.15\right)$. In the current model, the only way to reconcile the calculated and observed present day atmospheric ${ }^{4} \mathrm{He}$ values, would be to lower $k_{2}$ by an order of magnitude. Given that helium escape from the atmosphere is not isotope-specific, both $k_{1}$ and $k_{2}$ must be treated the same and thus cannot be used to resolve discrepancies in observed and calculated ${ }^{4} \mathrm{He}$ values.

In previous models (i.e. [3,4]), we assumed that noble gases transported into the continental crust remained there. However, helium is a relatively labile and tiny element and may degas from the continental crust into the atmosphere during weathering etc. We accounted for these degassing mechanisms in the present model as follows:

$$
\begin{aligned}
& d^{3} \mathrm{He}_{\mathrm{A}}(t) / d t={ }^{3} \mathrm{He} C_{\mathrm{D}} \cdot M_{\text {Dout }}(t) \\
& +{ }^{3} \mathrm{He} C_{\mathrm{L}} \cdot M_{\text {Lout }}(t)-k_{1} \cdot{ }^{3} \mathrm{He}_{\mathrm{A}}(t)+d^{3} \mathrm{He}_{\mathrm{cc}}(t) / d t, \\
& d^{4} \mathrm{He}_{\mathrm{A}}(t) / d t={ }^{4} \mathrm{He} C_{\mathrm{D}} \cdot M_{\text {Dout }}(t) \\
& +{ }^{4}{ }^{4} C_{\mathrm{L}} \cdot M_{\text {Lout }}(t)-k_{2} \cdot{ }^{4} \mathrm{He}_{\mathrm{A}}(t)+d^{4} \mathrm{He}_{\mathrm{cc}}(t) / d t,
\end{aligned}
$$

where the subscript cc represents continental crust. We assume that all the helium in the continental crust degasses to the atmosphere.

Under these conditions, we obtain the results shown in Figure 5. Values for ${ }^{3} \mathrm{He}$ (Figure 5(a)) calculated from this crust degassing model are almost the same as those of the previous model (shown in Figure 4(a)), indicating that the amount of ${ }^{3} \mathrm{He}$ in the continental crust is negligible relative to ${ }^{3} \mathrm{He}$ contents of the atmosphere. Values for ${ }^{4} \mathrm{He}$ calculated in the crust-degassing model (Figure 5(b)) however are markedly different from the non-degassing scenario shown in Figure 4(b). This suggests that the radiogenic ${ }^{4} \mathrm{He}$ produced from $\mathrm{U}$ and $\mathrm{Th}$ in the continenttal crust is relatively large. The calculated value for present day atmospheric ${ }^{4} \mathrm{He}$ (Figure 5(b)) is about an order of magnitude higher than that of the non-degassing scenario shown in Figure 4(b), and is close to the observed present day atmospheric value. The corresponding ${ }^{3} \mathrm{He} /{ }^{4} \mathrm{He}$ ratio calculated in the crust-degassing model is also consistent with observed atmospheric values (Figure 5(c)). This ratio decreases rapidly during the first several million years of Earth history, then changes slowly, and shows little change over the last 0.1 billion years. The ${ }^{3} \mathrm{He} /{ }^{4} \mathrm{He}$ ratio at $0.1 \mathrm{Ga}$ is only $10 \%-12 \%$ higher than the present day value.

\subsection{Comparison of Measured Fossil He and Ar Values with Model He and Ar Trajectories}

The Ar and He isotopic ratios obtained from fossil material were fairly consistent with present day atmospheric values although there is some addition of radiogenic component. We plotted the isotopic ratios versus age
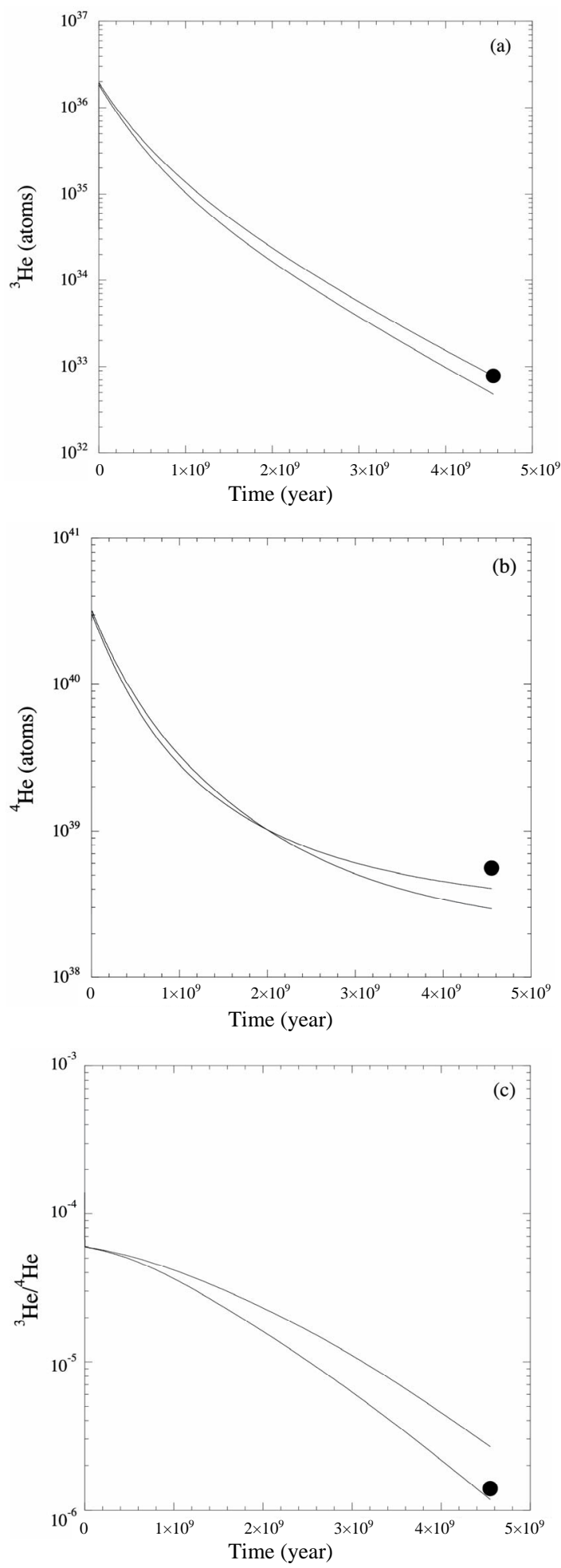

Figure 5. Time versus (a) ${ }^{3} \mathrm{He}$ abundance (atoms); (b) ${ }^{4} \mathrm{He}$ abundance (atoms); and (c) ${ }^{3} \mathrm{He} /{ }^{4} \mathrm{He}$ ratio in the atmosphere, assuming complete helium degassing from the continental crust to the atmosphere. The two lines correspond to the upper and lower limits derived from the present day concentration of ${ }^{40} K$ in the continental crust and in the depleted mantle (for details, see [4]). The closed circle represents the observed present day atmospheric values. 
along with isotopic trajectories from the mathematical models in Figure 6. The age is given as "B. P." (present day at time zero) and represented on a logarithmic scale. For Ar, we plotted ${ }^{40} \mathrm{Ar} /{ }^{36} \mathrm{Ar}_{\text {corrected }}$ ratios after making the correction for the mass fractionation effect. Figure 6 clearly indicates that $\mathrm{Ar}$ and He isotopic ratios have been nearly constant for the last 1 and 0.1 billion years, respectively. The ages of fossils analyzed in this study fell
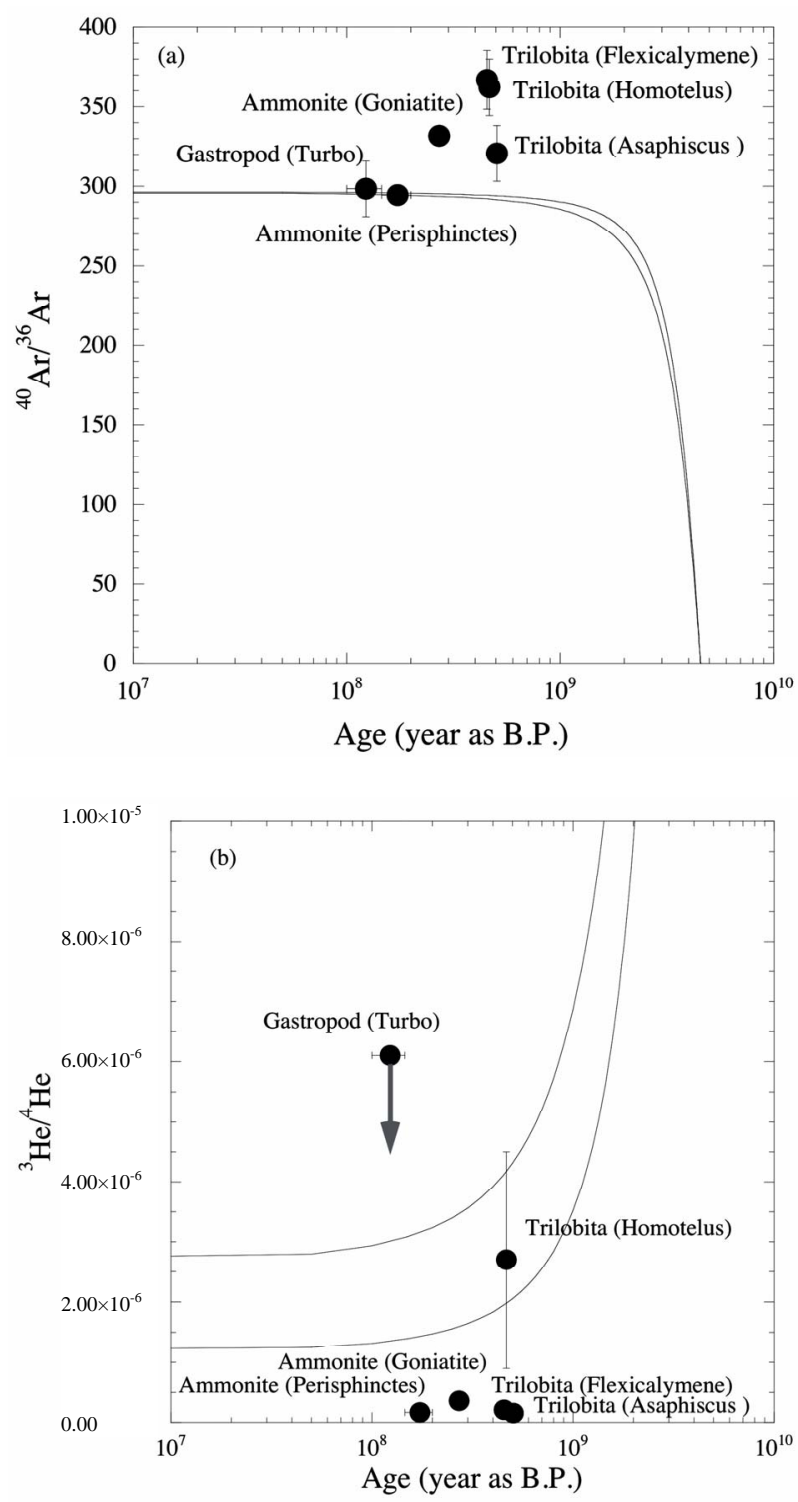

Figure 6. Comparison of (a) ${ }^{40} \mathrm{Ar} /{ }^{36} \mathrm{Ar}$ ratios (corrected for the mass fractionation effect) and (b) ${ }^{3} \mathrm{He} /{ }^{4} \mathrm{He}$ ratios measured from fossil material with corresponding trajectories of Ar and He isotopic evolution through time from mathematical models. The two trajectories correspond to the upper and lower limits derived from the present day concentration of ${ }^{40} \mathrm{~K}$ in the continental crust and in the depleted mantle (see the captions of Figures 4 and 5). Here, age is represented on a logarithmic scale in years before present (B. P.). between $10^{8}$ and $10^{9}$ years, a range consistent with the range of their known stratigraphic ages. Considering that the isotopic ratios are represented on a linear scale, the measured ${ }^{40} \mathrm{Ar} /{ }^{36} \mathrm{Ar}$ ratios in fossils were the values slightly higher than those given by the mathematical model. We attribute the variation relative to the model trajectory to a radiogenic component within the fossil material (Figure 6(a)). Similarly, a plot of fossil ${ }^{3} \mathrm{He} /{ }^{4} \mathrm{He}$ ratios versus age relative to the predicted isotopic trajectory (model) indicates the addition of radiogenic ${ }^{4} \mathrm{He}$. We interpret the similarity of these ratios to the present day atmosphere that the measured isotopic ratios are not simply the result of sample contamination by the present day atmosphere. Our models suggest that ${ }^{40} \mathrm{Ar} /{ }^{36} \mathrm{Ar}$ and ${ }^{3} \mathrm{He} /{ }^{4} \mathrm{He}$ ratios in the ages of fossils also indicate the similar values to the present day atmosphere. The relatively high ${ }^{40} \mathrm{Ar} /{ }^{36} \mathrm{Ar}$ ratios and low ${ }^{3} \mathrm{He} /{ }^{4} \mathrm{He}$ ratios measured from fossil material are likely to reflect the addition of radiogenic component from gas-mineral exchange within the fossil matrix to the trapped ancient atmosphere.

\section{Conclusion}

We measured elemental abundances and isotopic ratios of $\mathrm{He}$ and $\mathrm{Ar}$ in fossil material of varying age, using a large, closed system crushing apparatus. The elemental abundances of radiogenic component of $\mathrm{He}$ and $\mathrm{Ar}$ are between the present day atmospheric value and those estimated from the radiogenic decay product from the continental crust. The measured ${ }^{3} \mathrm{H} /{ }^{4} \mathrm{He}$ ratios were lower than the corresponding present day atmospheric value, whereas measured ${ }^{40} \mathrm{Ar} /{ }^{36} \mathrm{Ar}$ ratios were higher than the present day atmospheric value. These isotopic ratios in fossils therefore indicate the addition of a radiogenic component to He and Ar contents that are similar to present day atmospheric values. These results may indicate that the fossil's void space has exchanged gas with the present atmosphere. However, results from a mathematiccal model of atmospheric He and Ar isotopic ratios through time offer an additional explanation. The model results specifically suggest that He and Ar isotopic ratios have been nearly constant for the last 0.1 and 1 billion years, respectively. It is therefore possible that the fossils retained ancient atmospheric signatures in their void space, along with a radiogenic component incorporated from solids and released during the crushing procedure.

\section{REFERENCES}

[1] H. Brown, "Rare Gases and the Formation of the Earth's Atmosphere," In: C. P. Kuiper, Ed., The Atmospheres of the Earth and Planets, University of Chicago Press, Chi- 
cago, 1952, pp. 258-266.

[2] G. Turner, "The Outgassing History of the Earth's Atmosphere," Journal of the Geological Society of London, Vol. 146, No. 1, 1987, pp. 147-154. doi:10.1144/gsjgs.146.1.0147

[3] K, Kamijo, K. Hashizume and J. Matsuda, "Noble Gas Constraints on the Evolution of the Atmosphere-Mantle System," Geochimica et Cosmochimica Acta, Vol. 62, No. 13, 1998, pp. 2311-2321. doi:10.1016/S0016-7037(98)00163-X

[4] A. Seta, T. Matsumoto and J. Matsuda, "Concurrent Evolution of ${ }^{3} \mathrm{He} /{ }^{4} \mathrm{He}$ Ratio in the Earth's Mantle Reservoirs for the First 2 Ga," Earth and Planetary Science Letters, Vol. 188, No. 1-2, 2001, pp. 211-219. doi:10.1016/S0012-821X(01)00307-7

[5] J. Matsuda and B. Marty, “The ${ }^{40} \mathrm{Ar} /{ }^{36} \mathrm{Ar}$ Ratio of the Undepleted Mantle; a Reevaluation,” Geophysical Research Letters, Vol. 22, No. 15, 1995, pp. 1937-1940. doi:10.1029/95GL01893

[6] M. Ozima, "Noble Gas State in the Mantle,” Review of Geophysics, Vol. 32, No. 4, 1994, pp. 405-426. doi:10.1029/94RG01875

[7] J. Matsuda, T. Maruoka, D. L. Pinti and C. Koeberl, "Noble Gas Study of a Philippinite with an Unusually Large Bubble,” Meteoritics and Planetary Science, Vol. 31, No. 2, 1996, pp. 273-277. doi:10.1111/j.1945-5100.1996.tb02023.x

[8] J. Matsuda, M. Namba, T. Maruoka, T. Matsumoto and G. Kurat, "Primordial Noble Gases in a Graphite-Metal Inclusion from the Canyon Diablo IAB Meteorite and Their Implications,” Meteoritics and Planetary Science, Vol. 45, No. 3, 2005, pp. 361-372. doi:10.1111/j.1945-5100.2010.01026.x

[9] J. Matsuda, H. Tsukamoto, C. Miyakawa and S. Amari, "Noble Gas Study of the Saratov L4 Chondrite," Meteoritics and Planetary Science, Vol. 45, No. 3, 2010, pp. 361-372. doi:10.1111/j.1945-5100.2010.01026.x

[10] J. Matsuda, T. Matsumoto, H, Sumino, K. Nagao, J. Yamamoto, Y. Miura, I. Kaneoka, N. Takahata and Y. Sano, "The ${ }^{3} \mathrm{He} /{ }^{4} \mathrm{He}$ Ratio of the New Internal He Standard of Japan (HESJ)," Geochemical Journal, Vol. 36, No. 2, 2002, pp. 191-195. doi:10.2343/geochemj.36.191

[11] S. R. Taylor, "Solar System Evolution. A New Perspective," 2nd Edition, Cambridge University Press, Cambridge, 2001. doi:10.1017/S1360641701342788

[12] K. P. Jochum, A. W. Hofmann, E. Ito, H. M. Seufert and W. M. White, "K, U and Th in Mid-Ocean Ridge Basalt Glasses and Heat Production, K, U and K/Rb in the Mantle,” Nature, Vol. 306, 1983, pp. 431-436. doi:10.1038/306431a0

[13] T. Matsumoto, A. Seta, J. Matsuda, M. Takebe, Y. Chen and S. Arai, "Helium in the Archean Komatiites Revisited: Significantly High ${ }^{3} \mathrm{He} /{ }^{4} \mathrm{He}$ Ratios Revealed by Fractional Crushing Gas Extraction," Earth and Planetary Science Letters, Vol. 196, No. 3-4, 2002, pp. 213-225. doi:10.1016/S0012-821X(01)00602-1

[14] D. Porcelli and G. J. Wasserburg, "Mass Transfer of Xenon through a Steady-State Upper Mantle," Geochimica et Cosmochimica Acta, Vol. 59, No. 10, 1995, pp. 19912007. doi:10.1016/0016-7037(95)00122-0

[15] D. Porcelli and G. J. Wasserburg, "Mass Transfer of Helium, Neon, Argon, and Xenon through a Steady-State Upper Mantle," Geochimica et Cosmochimica Acta, Vol. 59, No. 23, 1995, pp. 4921-4937. doi:10.1016/0016-7037(95)00336-3

[16] J. Matsuda and K. Matsubara, "Noble Gases in Silica and Their Implication for the Terrestrial 'Missing' Xe,” Geophysical Research Letters, Vol. 16, No. 1, 1989, pp. 8184. doi:10.1029/GL016i001p00081

[17] T. Matsumoto, Y. Chen and J. Matsuda, "Concomitant Occurrence of Primordial and Recycled Noble Gases in the Earth's Mantle,” Earth and Planetary Science Letters, Vol. 185, No. 1-2, 2001, pp. 35-47. doi:10.1016/S0012-821X(00)00375-7

[18] D. R. Hilton, K. Hammerschmidt, G. Loock and H. Friedrichsen, "Helium and Argon Isotope Systematics of the Central Lau Basin and Valu Fa Ridge: Evidence of Crust/Mantle Interactions in a Back-Arc Basin," Geochimica et Cosmochimica Acta, Vol. 57, No. 12, 1993, pp. 2819-2841. doi:10.1016/0016-7037(93)90392-A

[19] M. Honda, I. MacDougall, D. B. Patterson, A. Doulgeris and D. S. Clague, "Noble Gases in Submarine Pillow Basalt Glasses from Loihi and Kilauea, Hawaii: A Solar Component in the Earth," Geochimica et Cosmochimica Acta, Vol. 57, No. 4, 1993, pp. 859-874. doi:10.1016/0016-7037(93)90174-U

[20] P. Burnard, D. Graham and G. Turner, "Vesicle-Specific Noble Gas Analysis of 'Popping Rock': Implications for Primordial Noble Gases in Earth,” Science, Vol. 276, 1997, pp. 568-571. doi:10.1126/science.276.5312.568

[21] R. K. O’Nions, S. R. Carter, N. M. Evensen and P. J. Hamilton, "Upper Mantle Geochemistry,” The Sea, Vol. 7, 1981, pp. 49-71.

[22] G. Kockart, "Helium in the Terrestrial Atmosphere," Space Science Reviews, Vol. 14, 1973, pp. 723-757.

[23] M. Ozima and F. A. Podsek, "Noble Gas Geochemistry," 2nd Edition, Cambridge University Press, Cambridge, 2002. 